\title{
Analysis of Eddy Formation and Heat Transfer Process in Weld Pool during Plasma Keyhole Arc Welding
}

\author{
Manh Huu Ngo ${ }^{1,+}$, Anh Van Nguyen ${ }^{2,3, *,+}$, Thanh Tam Nguyen ${ }^{4}$, Dang Hai Tran ${ }^{5}$, Hai Thanh \\ Nguyen $^{6}$ \\ 1 Science-Technology and International Cooperation Department, Sao do University, Hai Duong, Vietnam; \\ manh.weldtech@gmail.com \\ 2 Research and Development Department, Murata Welding Laboratory, Osaka 5320012, Japan; \\ ann@mwl.co.jp \\ 3 School of Mechanical Engineering, Hanoi University of Science and Technology, Hanoi, Vietnam \\ ann@mwl.co.jp \\ 4 Faculty of Mechanical Engineering, Maritime University, Hai Phong, Vietnam; \\ phamtamthanh@vimaru.edu.vn \\ 5 Faculty of Mechanical Engineering, Sao do University, Hai Duong, Vietnam; \\ 6 Faculty of Mechanical Engineering, Ho Chi Minh University of Technology, Ho Chi Minh, Vietnam; \\ haint@hcmut.edu.vn \\ * Correspondence: ann@mwl.co.jp \\ + Authors contributed equally to this work, they are considered as co-first author.
}

\begin{abstract}
This investigation aims to discuss the formation process of eddies and the heat transportation in plasma keyhole arc welding. In order to clarify this issue, the measurement of the convection inside the weld pool, the convection on the weld pool surface, also the temperature distribution on the weld pool surface were carried out. The results showed that two eddies were found in the weld pool, which is controlled mainly through the shear force by the plasma flow acting on the weld pool surface. The magnitude, extent and direction of the shear force are thought to be determined primarily by the variation of keyhole profile. The relative shape and strength of each eddy is largely changed depending on the change of the keyhole profile when nozzle diameter changed. These relative strengths of each eddy are considered to decisively govern the heat transport in the weld pool coinciding with the direction of eddies. A larger eddy near the lower part of the keyhole inside the weld pool was found out in the case of $1.6 \mathrm{~mm}$, meanwhile a upward larger eddy was found out near the upper part of the keyhole inside the weld pool in the case of $2.4 \mathrm{~mm}$.
\end{abstract}

Keywords: Plasma keyhole arc welding, X-ray observation, Heat transportation, Eddy, Convective pattern, Temperature measurement, Nozzle diameter

\section{Introduction}

Plasma keyhole arc welding (PKAW) is one of fusion welding processes [1, 2]. PKAW process is characterized by a "keyhole" inside the weld pool caused by the plasma arc from the torch impinges on the entire thickness of base metal [3]. Due to using a constriction nozzle, the plasma arc in PKAW is concentrated in comparison with TIG welding. This leads to increase the current density, the heat flux and arc pressure under the thermal pinch effect [4]. Because PKAW has better advances over conventional TIG welding and GMA welding in welding mid-thickness plates [5], and laser beam welding and electron beam welding in equipment cost, safety condition, and operation convenience [6], it has been utilized to join the structures of aerospace [7], automobile [8], rocket [9] and structural steel [10], aluminium [11,12], etc. 
In PKAW process, after arc ignition, the base metal starts to be melted by high heat flux, and immediately, molten metal is pushed down by high arc pressure to form a "close keyhole" on base metal surface. Under sufficiently high heat flux and arc pressure, the close keyhole continues to grow and, eventually, the base material is fully penetrated to form an "open keyhole". In case of having a related movement between torch and base metal, the molten metal produced in front of the keyhole is transported in backward direction through both sides of the keyhole to merge behind the keyhole. As a result, the weld pool is produced in the rear region. The weld pool in the rear region is formed through the heat transportation primarily due to the weld pool convection driven by Shear force, Marangoni force, Lorentz force and Buoyancy force, with Shear force and Marangoni force are considered to depend on the keyhole profile significantly and the weld pool surface temperature distribution. This molten metal is held by surface tension of the weld pool to prevent burn through. As implied above, there is a strong interaction among plasma arc characteristic - keyhole profile weld pool temperature - weld pool convection, indicating that PKAW is a complexity process. Besides, the formation of keyhole and weld pool is easy to become unstable in order to induce various welding defects, due to the change of parameters during welding caused by disturbance. Therefore, in order to obtain a high-quality weld joint, it is essential to deeply understand the relationship of the arc-keyhole-temperature and weld pool in details through which the keyhole and the weld pool are formed.

In order to control efficiently this process, many papers so far focused on elucidate the keyhole formation process by detecting and measuring the keyhole situation in real-time. Metcalfe et al. [13] measured the efflux plasma from the backside of keyhole to indicate the period of opening keyhole. In other efforts, Zhang et al. [14] attempted to detect the variety states of keyhole using a sensor catching plasma cloud from top surface. These approaches are simple and convenient indirect observations, but they cannot provide the information of keyhole and weld pool profile. Recently, Wu et al. [15-17] have developed a new vision system for observing the keyhole and weld pool simultaneously from the bottom surface of base metal. This system allows to identify sizes and behaviours of the keyhole and weld pool with high reliability. This system can largely save the cost for the observation compared with a laser-strobe system [18]. The temperature distribution around the keyhole and on weld pool surface has great influence on the formation and stability of keyhole. Therefore, simultaneous sensing of both the keyhole and weld pool from the bottom surface, as well their surrounding temperature distribution in real time under different levels of welding current was conducted [19].

Observation of keyhole and weld pool as mentioned above is important to understand weld phenomena. Based on observation results above, this process can be controlled to obtain better joints quality. Wu team [20] have developed "One pulse one open keyhole" process using pulsed waveform current to control the keyhole state from open to close periodically. This process is utilized with the above real-time sensing methods of the keyhole state. And it is able to control heat input optimally to avoid formation of porosity and burn-through.

Furthermore, mechanism of PKAW process are closely related weld pool phenomena as indicated above. However, due to the difficulty of measurement of weld pool convection, especially the convection inside weld pool, there were very few reports of the experimental studies on the weld pool formation process. Therefore, theoretical researches through numerical simulation have been mainly carried out as an alternative approach to overcome this issue. Wu's team [21-23] utilized twodimensional and three-dimensional models of stainless steel considering the coupled arc - weld pool - keyhole interactions for analyzing heat transportation and fluid flow inside the weld pool. The results indicated that the highest temperature is located around the keyhole and it decreased far from the keyhole in the radial direction. The results also indicated that there are two convective flows inside the weld pool: (1) one convection in outwards direction along the top surface of weld pool and (2) another one in downward direction along the keyhole wall. In a recent paper, Pan et al. [24] have computed the convective patterns of the weld pool in case of stationary PKAW of aluminum using a coupled model assuming an axial symmetric domain. They predicted that there are two convective patterns of weld pool in this case. One convective pattern on the weld pool surface outwards is mainly 
inducted by plasma gas flow and Marangoni force. Whereas, another convective pattern inwards from the weld pool boundary is caused by Lorentz force. However, actually welding conditions in factories and industries were totally different to stationary case.

As described above, in recent years, predictions on the weld pool formation process considering the interaction with the keyhole formation have been made. However, a whole picture of the relationship among plasma arc characteristics - keyhole formation - wed pool temperature and weld pool convection has not been clarified yet. In order to obtain the deeper understanding, a comprehensive investigation including experimental measurement and simulation of the weld pool phenomena is indispensable. Furthermore, as indicated above, the weld pool phenomena are related to the activation of driving forces. Driving forces in fusion welding processes were controlled mainly by welding parameters such as: plasma gas flow rate, nozzle diameter, welding speed, etc. [25].

Therefore, in this work the relationship among the formation process of eddies inside the weld pool with the change of the keyhole profile, and the heat transformation is discussed details.

\section{Experimental Method}

\subsection{Common experimental setup and welding conditions}

This paper utilized three measurement methods to study welding phenomena. This subsection explains the common experimental setup and the welding conditions. The welding equipment consists of a transfer-type plasma arc welding torch $(100 \mathrm{WH}$, Nippon Steel Welding \& Engineering Co., Ltd) and a welding power source (NW-300ASR, Nippon Steel Welding \& Engineering Co., Ltd). The nozzle dimeters are $1.6 \mathrm{~mm}$ and $2.4 \mathrm{~mm}$. The electrode setback is $3 \mathrm{~mm}$. The distance between the nozzle and the base metal is approximately $5 \mathrm{~mm}$. The base metal is a stainless steel SUS304 with the dimension of $300 \mathrm{~mm} \times 100 \mathrm{~mm} \times 4 \mathrm{~mm}$. The base metal is moved by an actuator at the constant welding speed of $3 \mathrm{~mm} / \mathrm{s}$. Welding current is set at DC120A. Shielding gas and plasma gas (pilot gas) are pure Ar, and their flow rates are $6.01 / \mathrm{min}$ and $1.5 \mathrm{l} / \mathrm{min}$ respectively. For protecting the backside of weld pool, a back-shielding gas box is put on the welding jig. The shielding gas flow rate of $5 \mathrm{l} / \mathrm{min}$ is introduced into the back-shielding gas box in order to prevent the negative influence of air on welding quality. The details for each observation methods and other welding conditions are explained in the subsequent sections.

\subsection{Measurement of temperature distribution on weld pool surfaces}

Temperature distribution on weld pool surfaces (top surface and bottom surface) are captured by a high temperature measurement system [26]. A schematic illustration of temperature distribution measurement on the weld pool surfaces is denoted in Fig. 1. Here, camera is setup at a frame rate of $2000 \mathrm{fps}$. A lens (Sigma DG28-300, Nikkon Co., Ltd) is utilized to adjust the magnification of images. Due to strong radiation and intensity of the arc, the image is captured immediately after switching off the main arc (within $0.001 \mathrm{~s}$ after cutting arc). It is confirmed in a recent paper that the decreased temperature during the cutting arc is enough small to be ignorable [26]. Then, the temperature distribution is computed from the ratio of $R$ sensor signal to $G$ sensor signal in the image by Thermera-HS software. 


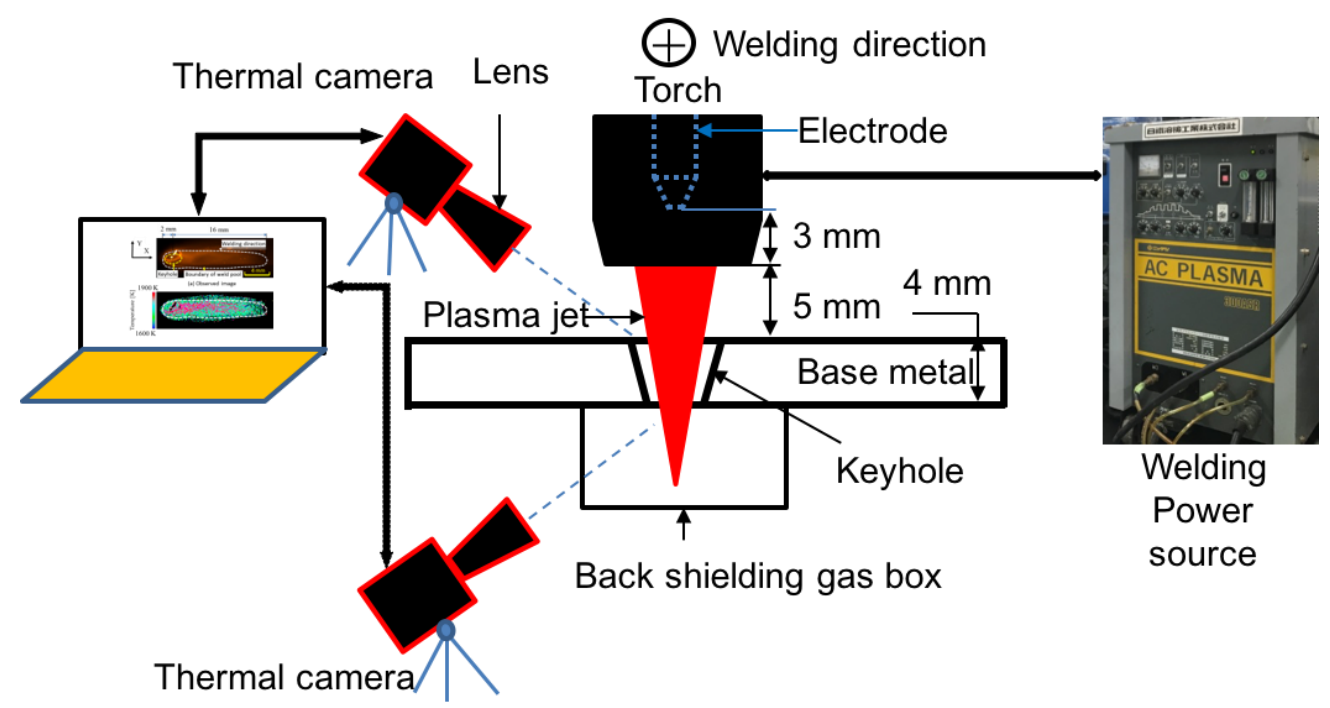

Fig 1. Schematic illustration of temperature distribution measurement.

\subsection{Observing the convective patterns on the weld pool surfaces.}

Measurement of convection of weld pool surfaces is carried out for both the top surface and bottom surfaces based on the movement of tracer (small zirconia particles). Schematic illustration of experimental setup for the observation is shown in Fig. 2. Here, a high-speed video camera (HSVC) connected to a laptop takes photographs at $3000 \mathrm{fps}$. A band-pass filter for the wavelength of $550 \mathrm{~nm}$ is attached in front of HSVC to prevent the relatively strong radiation of the arc. In addition, the magnification of weld pool images is controlled by a lens (Micro-Nikkon $105.0 \mathrm{~mm} \mathrm{f/2.8,} \mathrm{Nikkon} \mathrm{Co.,}$ Ltd). Zirconia particles with the diameter of $0.05 \mathrm{~mm}$ are used as tracer particles.

In order to measure convective patterns, the zirconia particles were put into small holes on the top surface of base metal before each experiment. Some particles are transported from the top surface toward the bottom surface through the keyhole. Some of them are moved upwards and backwards on the top surface. During welding period, the movement of zirconia particles are captured. After that, a software for analyzing fluid flow (Dipp-motion, Detect Co., Ltd) is used to analyze the behavior of convective patterns.

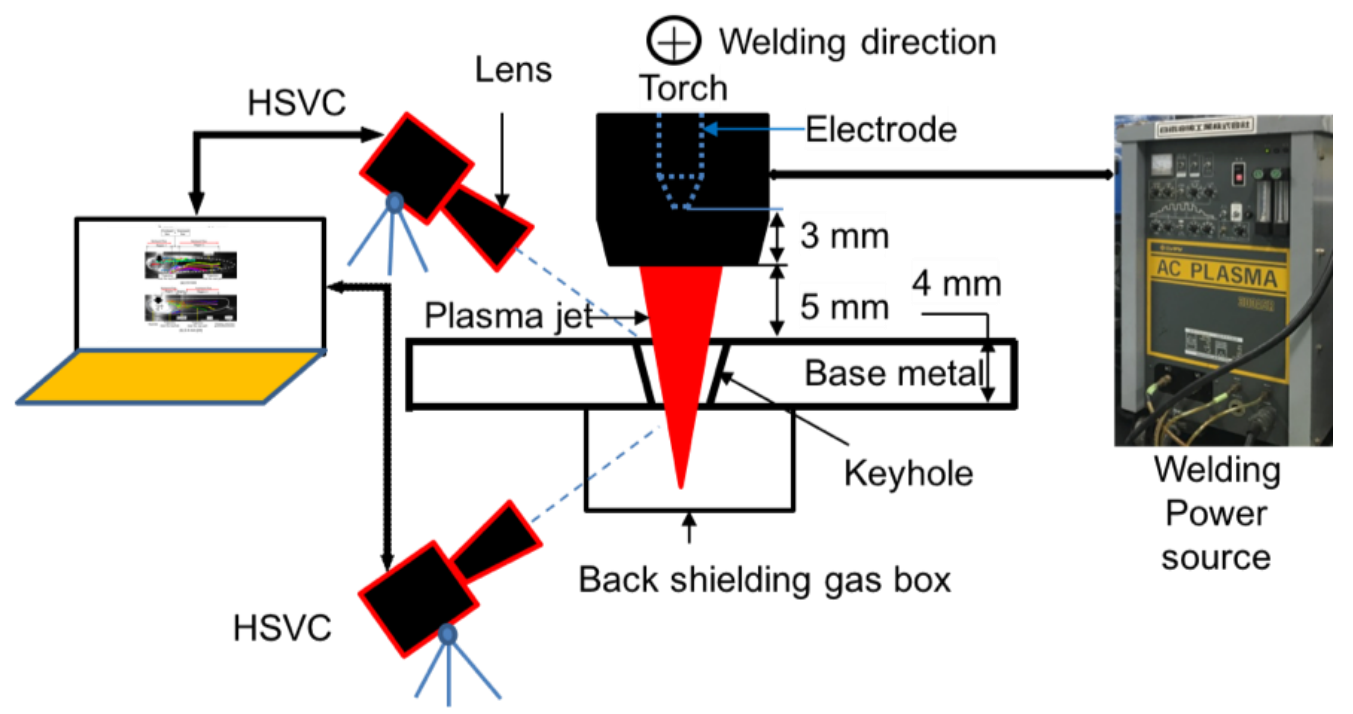

Fig 2. Schematic illustration of experimental setup for observing the convective patterns on the weld pool surfaces. 


\subsection{Observing the convective patterns inside the weld pool.}

The main equipment utilized is a 4-dimensional X-ray observation system. A schematic illustration of this system is indicated in Fig. 3. This system consists of two sets of X-ray power sources, HSVCs and image intensifiers. The X-ray 1 power source is setup from the upper side of the base metal. Its power source outputs tube current of $3.5 \mathrm{~mA}$ and tube voltage of $225.0 \mathrm{kV}$. Meanwhile, the X-ray 2 power source is set up from the lower side of the base metal. Its power source outputs tube current of $1.0 \mathrm{~mA}$ and tube voltage of $230.0 \mathrm{kV}$. The tilt angle between each of the incident $X-$ rays and the horizontal plane of base metal is fixed at 300 . The incident $X$-rays cut each other at the centre point of the keyhole on the neutral plane of base metal. In this setting, X-ray transmission images are captured by two HSVCs at the same frame rate of $1000 \mathrm{fps}$. Subsequently, the trigger signals of the HSVCs are synchronically controlled. In order to estimate convective patterns, tungsten particles with diameter of $0.5 \mathrm{~mm}$ are employed as tracer. In each experiment, one tungsten particle is put into a hole on the base metal surface. The convective patterns are therefore determined from the behaviour of the tungsten particles during welding.

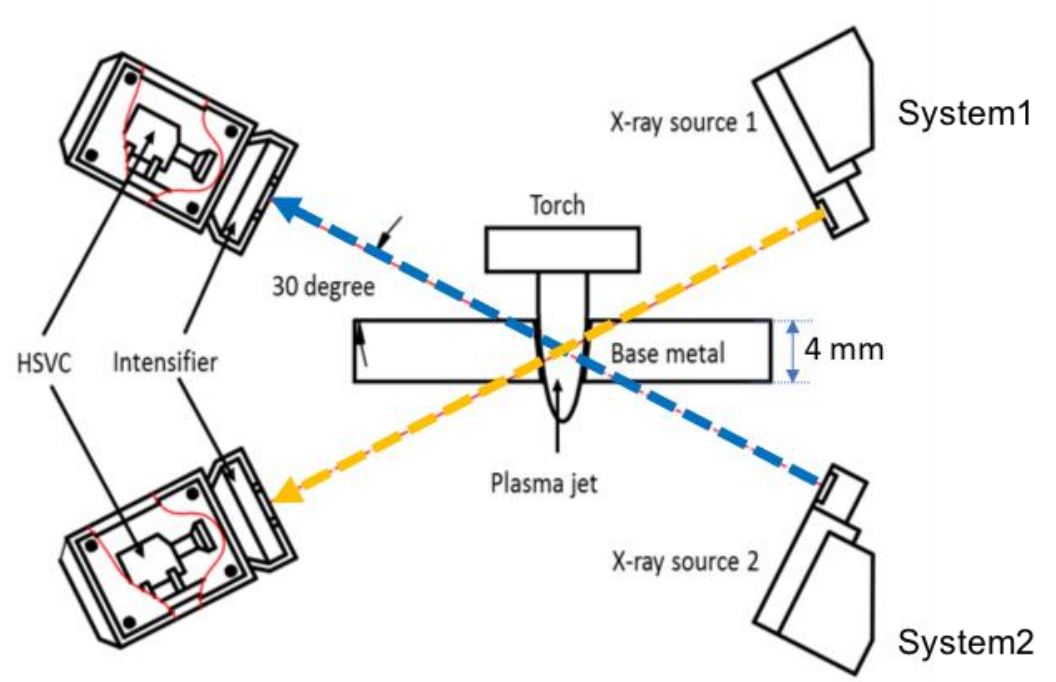

Fig 3. Schematic illustration of X-ray observation system.

\section{Experimental Results}

For all the data processing in this paper, a Descartes coordinate system including three coordinate axes (X-axis, Y-axis, and Z-axis) was set up as drawn in Fig. 4. X-axis is a parallel to welding direction and coincident with the centre line of weld pool. Y-axis is a perpendicular to the welding direction and a parallel to weld pool surface. Z-axis is a parallel to the direction of gravity force through the centre of the keyhole on the bottom surface. The origin $(X=0 ; Y=0 ; Z=0)$ is chosen on the top surface at the intersected point of three axes $\mathrm{X}$-axis, $\mathrm{Y}$-axis and $\mathrm{Z}$-axis. 


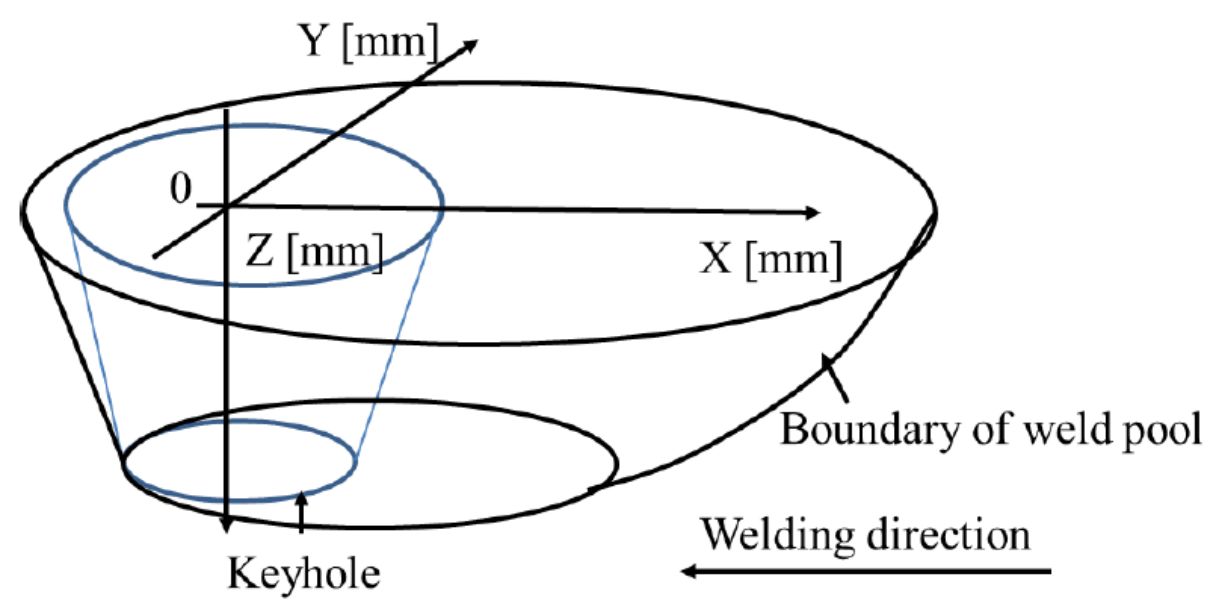

Fig 4. Schematic illustration of the coordinate system.

\subsection{Weld bead apperacne}

Weld bead appearance and keyhole profile are exhibited in Fig. 5 (a) and (b) corresponding to nozzle diameter of $1.6 \mathrm{~mm}$ and $2.4 \mathrm{~mm}$ respectively. Weld bead width on the top surface is about 5.4 $\mathrm{mm}$ in the case of $1.6 \mathrm{~mm}$ and about $6.8 \mathrm{~mm}$ in the case of $2.4 \mathrm{~mm}$. Weld bead width on the bottom surface is about $2.5 \mathrm{~mm}$ and $2.8 \mathrm{~mm}$ in the cases of $1.6 \mathrm{~mm}$ and $2.4 \mathrm{~mm}$, respectively. The keyhole size on top surface is about $4.4 \mathrm{~mm}$ in the case of $1.6 \mathrm{~mm}$ and $4.8 \mathrm{~mm}$ in the case of $2.4 \mathrm{~mm}$. On bottom surface, it is about $2.1 \mathrm{~mm}$ and $2.3 \mathrm{~mm}$, respectively. On the other hand, the inclination angle of rear edge of keyhole wall is much increased in the case of $2.4 \mathrm{~mm}\left(23^{\circ}\right)$ compared to the case of $1.6 \mathrm{~mm}$ $\left(13^{\circ}\right)$. Meanwhile, the inclination angle of front edge of keyhole surface is about $13^{0}$ in in the case of $1.6 \mathrm{~mm}$ and $14^{0}$ in the case of $2.4 \mathrm{~mm}$. The distance between the centre line of torch and the centre line of keyhole on the bottom surface was increased in the case of $2.4 \mathrm{~mm}$ due to the decrease of arc pressure and heat flux from the torch. As a result, keyhole and weld bead are bigger especially on the top surface in the case of $2.4 \mathrm{~mm}$. It can be also seen that weld bead appearance is well without undercut, convex, reinforcement, and burn-through in both cases.

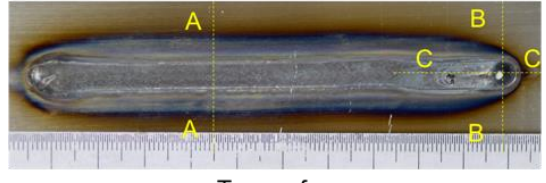

Top surface
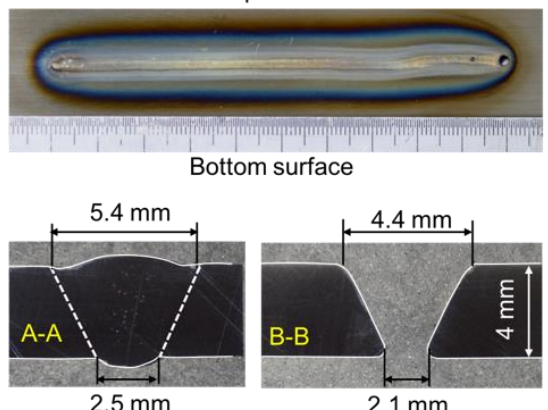

$2.5 \mathrm{~mm}$

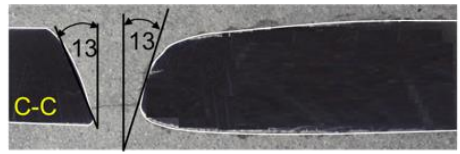

(a) $2.0 \mathrm{~m}$

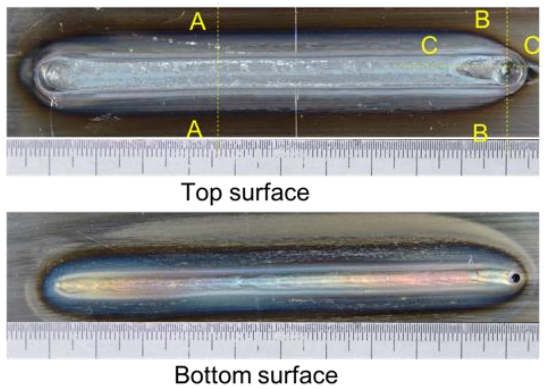

Bottom surface
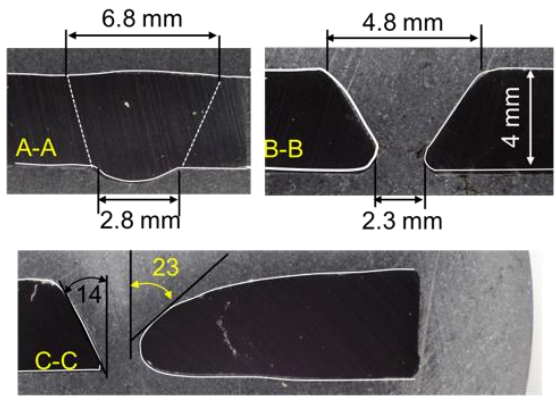

(b) $2.4 \mathrm{~mm}$

Fig 5. Weld bead appearance and keyhole profile. 


\subsection{Temperature distribution on weld pool surface}

Fig. 6 (a) and (b) presented observed images and temperature distribution on top surface in the case of $1.6 \mathrm{~mm}$ and $2.4 \mathrm{~mm}$, respectively. It can be seen that weld pool width is larger in the case of $2.4 \mathrm{~mm}$, especially around the keyhole. Due to the strength of plasma jet and shear force component on the top surface, the weld pool width in case of $2.4 \mathrm{~mm}$ was gradually decreased, and it is reached the minimal size at the ending region. Weld pool is longer in the case of $1.6 \mathrm{~mm}$ with about $17 \mathrm{~mm}$ and it is about $16 \mathrm{~mm}$ in the case of $2.4 \mathrm{~mm}$. Due to the strength shear force component in upwards in the case of $2.4 \mathrm{~mm}$, the front part of keyhole is longer in the case of $2.4 \mathrm{~mm}$. It was about $3.0 \mathrm{~mm}$ in the case of $2.4 \mathrm{~mm}$, and about $2.5 \mathrm{~mm}$ in the case of $1.6 \mathrm{~mm}$. Generally, as it can be seen in temperature distribution images that the temperature overall surface is higher in the case of $1.6 \mathrm{~mm}$ comparing with the case of $2.4 \mathrm{~mm}$. The maximal temperature just behind keyhole is higher in the case of $1.6 \mathrm{~mm}$ in comparison to the case of $2.4 \mathrm{~mm}$. The maximal temperature was about $1875 \mathrm{~K}$ at $X=3.0 \mathrm{~mm}$ in the case of $1.6 \mathrm{~mm}$ and about $1820 \mathrm{~K}$ at $X=5.0 \mathrm{~mm}$ in the case of $2.4 \mathrm{~mm}$. The minimal temperature at rear part of weld pool is about $1753 \mathrm{~K}$ at $\mathrm{X}=18 \mathrm{~mm}$ in the case of $1.6 \mathrm{~mm}$ and $1721 \mathrm{~K}$ at $X=15.7 \mathrm{~mm}$ in the case of $2.4 \mathrm{~mm}$. The temperature around keyhole was about $1850 \mathrm{~K}$ at $\mathrm{X}=1 \mathrm{~mm}$ in the case of $1.6 \mathrm{~mm}$ and about $1759 \mathrm{~K}$ at $\mathrm{X}=1 \mathrm{~mm}$ in the case of $2.4 \mathrm{~mm}$. It can be also considered that gradient of temperature in the case of $2.4 \mathrm{~mm}$ is higher than that in the case of $1.6 \mathrm{~mm}$ due to the ratio of temperature variation/weld pool length was higher in the case of $2.4 \mathrm{~mm}$. In both cases, high temperature zone is located behind keyhole several millimeters. The high temperature zone is shifted toward nearby keyhole in the case of $1.6 \mathrm{~mm}$ in comparison to the case of $2.4 \mathrm{~mm}$. It is about $\mathrm{X}=2.5$ $-4.5 \mathrm{~mm}$ in the case of $1.6 \mathrm{~mm}$ and about $\mathrm{X}=4.4 \sim 6.3 \mathrm{~mm}$ in the case of $2.4 \mathrm{~mm}$.

Fig. 7 (a) and (b) illustrates observed images and temperature distribution on the bottom surface in cases of $1.6 \mathrm{~mm}$ and $2.4 \mathrm{~mm}$. Keyhole and weld pool are larger and longer in case of $2.4 \mathrm{~mm}$ in comparison with the case of $1.6 \mathrm{~mm}$. Their lengths are about $13 \mathrm{~mm}$ in the case of $1.6 \mathrm{~mm}$ and $15 \mathrm{~mm}$ in the case of $2.4 \mathrm{~mm}$. In general, the temperature distribution overall surface is higher in the case of $1.6 \mathrm{~mm}$. There is only one gradually decreased tendency of the temperature in both cases from the keyhole toward the end part of weld pool. The maximal temperature just behind keyhole is higher in the case of $1.6 \mathrm{~mm}$. The maximal temperature was about $1862 \mathrm{~K}$ at $\mathrm{X}=1 \mathrm{~mm}$ in the case of $1.6 \mathrm{~mm}$. In the case of $2.4 \mathrm{~mm}$, it is about $1797 \mathrm{~K}$ at $\mathrm{X}=1 \mathrm{~mm}$. At the rear part of weld pool, it is about $1746 \mathrm{~K}$ at $\mathrm{X}=14 \mathrm{~mm}$ and $1717 \mathrm{~K}$ at $\mathrm{X}=15 \mathrm{~mm}$ in cases of $1.6 \mathrm{~mm}$ and $2.4 \mathrm{~mm}$ respectively.

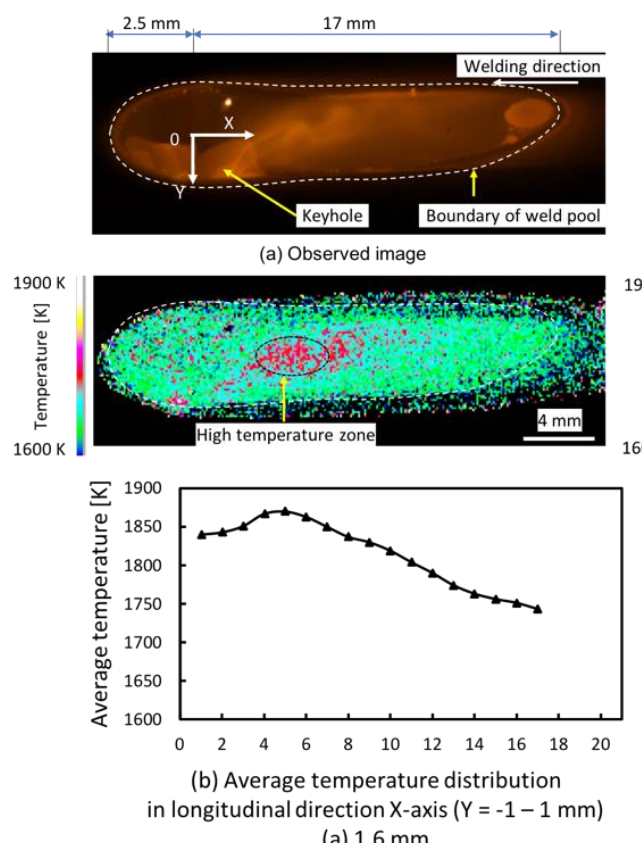

(a) $1.6 \mathrm{~mm}$

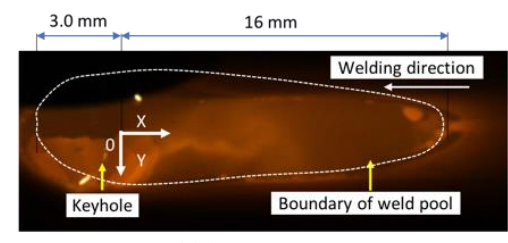

(a) Observed image
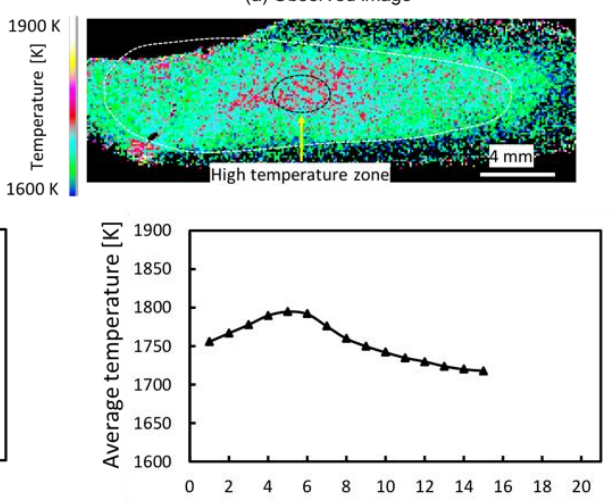

(b) Average temperature distribution in longitudinal direction $\mathrm{X}$-axis $(\mathrm{Y}=-1-1 \mathrm{~mm})$ (b) $2.4 \mathrm{~mm}$

Fig 6. Observed image and temperature distribution on the top surface of weld pool. 


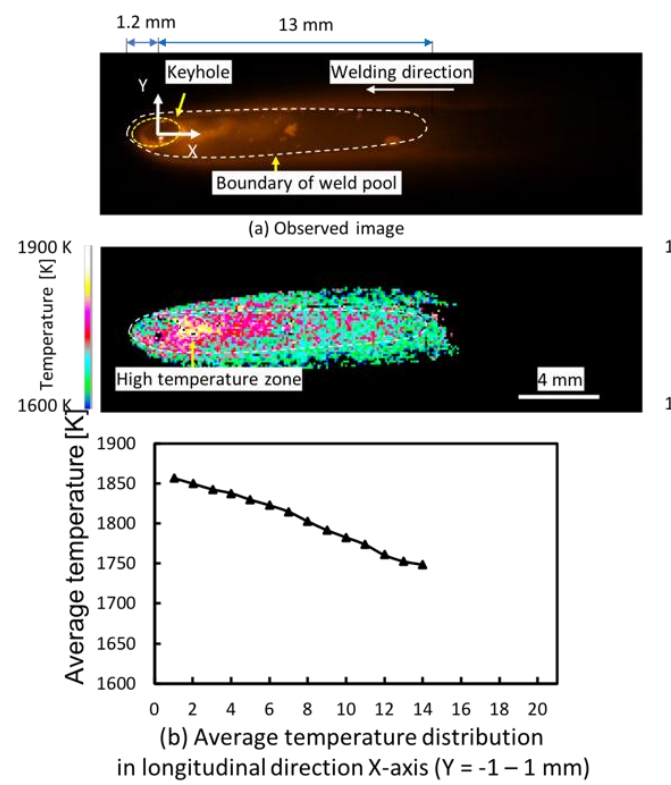

(a) $1.6 \mathrm{~mm}$

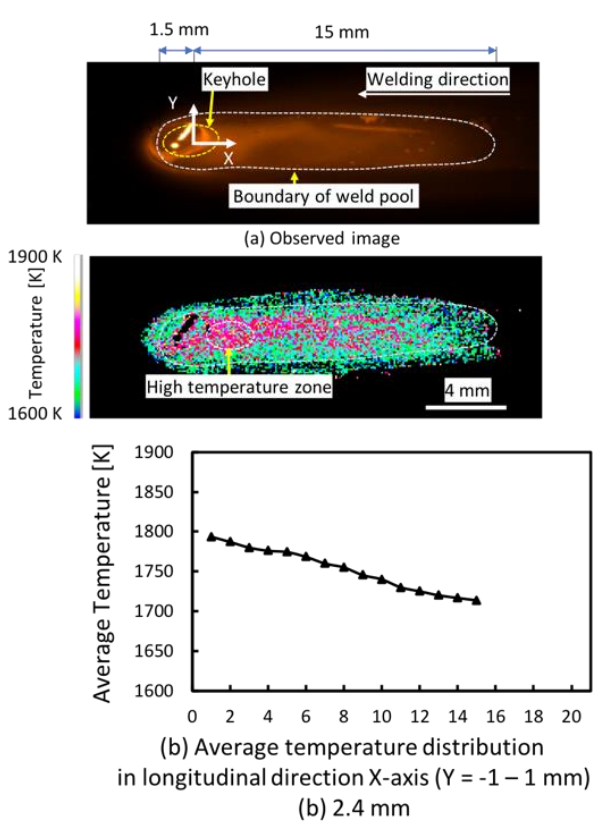

(b) $2.4 \mathrm{~mm}$

Fig 7. Observed image and temperature distribution on the bottom surface of weld pool.

\subsection{Convective patterns on weld pool surface}

Convective pattern on the top surface of the weld pool is exhibited in Fig. 8. As seen in Fig. 8 (a), in region 1 , the particles came from front edge of keyhole and moved with slow velocity toward the rear edge of keyhole. After passing the rear part of the keyhole about $1 \mathrm{~mm}$ along X-axis positive direction, several zirconia particles near the centre line of the weld pool are diverted the direction in order to move in frontwards toward the keyhole before moving in downward tendency toward the bottom surface. Meanwhile, several other zirconia particles far from the centre line of the weld pool are transported through both sides of the keyhole before accelerating in backwards toward region 2 . From region 2, particles were moved straight to the tail of the weld pool. As a consequence, there are two convective patterns within region 1: (i) in frontwards and downward tendency and (ii) in upward and backward tendencies. Meanwhile, there is only one convective pattern in backward tendency from behind keyhole toward the tail of weld pool at region 2. As seen in Fig. 8 (b), there is only one movement tendency of particles round region 1 in the case of $2.4 \mathrm{~mm}$. Zirconia particles are transported through both sides of the keyhole before accelerating in inward tendency and backward tendency toward region 2. Therefore, there is only one convective pattern in backward tendency at region 1 . At region 3 , since the particles are put around rear part of the weld pool, they are accelerated in frontward tendency toward region 2 . The highest velocity of particles occurred nearby before region 2. It can be considered that there is only a frontward convective pattern near the tail of the weld pool in this region. At region 2, the zirconia particles coming from region 1 and region 3 are altered from the translational motion to the circulated motion. As a result, there is a circulated convective pattern at region 2 within $X=4.2 \sim 6.3 \mathrm{~mm}$. The distribution of average flow velocity on the top surface is portrayed in Fig. 19 (a) and (b) corresponding to cases of $1.6 \mathrm{~mm}$ and $2.4 \mathrm{~mm}$, respectively. In the case of $2.0 \mathrm{~mm}$, the velocity of particles increased from front edge toward rear edge of the keyhole. It is about $0.18 \mathrm{~m} / \mathrm{s}$ at $X=-2.0 \mathrm{~mm}$, about $0.29 \mathrm{~m} / \mathrm{s}$ at $X=0.0 \mathrm{~mm}$, and about 0.48 $\mathrm{m} / \mathrm{s}$ at $X=0.5 \mathrm{~mm}$. After that, flow velocity is decreased a little bit before largely increasing to the maximal value at $X=2 \mathrm{~mm}$. It reached the maximal value about $0.63 \mathrm{~m} / \mathrm{s}$ nearby the rear edge of the keyhole $(X=2.1 \mathrm{~mm})$. From $X=2.1 \mathrm{~mm}$, the velocity is rapidly decreased to about $0.23 \mathrm{~m} / \mathrm{s}$ at $X=4.2$ $\mathrm{mm}$. From $X=4.0 \mathrm{~mm}$, the velocity is gradually decreased toward the end part of the weld pool. The minimal velocity at the end part of the weld pool $(X=11.5 \mathrm{~mm})$ is about $0.16 \mathrm{~m} / \mathrm{s}$. In the case of 2.4 $\mathrm{mm}$, for particles coming from front part of keyhole, they are accelerated in upward and backward tendencies at rear part of keyhole before reaching the maximal value about $0.52 \mathrm{~m} / \mathrm{s}$ behind keyhole 
at $X=2 \mathrm{~mm}$. Afterwards, the particles decreased the velocity toward the circulated motion zone (region 2) at $X=4.5 \sim 6.5 \mathrm{~mm}$. The minimal velocity at region 2 is about $0.13 \mathrm{~m} / \mathrm{s}$ at $X=4.5 \mathrm{~mm}$ and $X$ $=6.5 \mathrm{~mm}$. For particles coming from tail of weld pool, their velocity is gradually increased in frontward tendency from region 3 toward region 2 . The maximal velocity reached about $0.32 \mathrm{~m} / \mathrm{s}$ at $X=12.5 \mathrm{~mm}$ before decreasing to $0.15 \mathrm{~m} / \mathrm{s}$ nearby region 2 . The velocity of particles at end part of region 3 is about $0.08 \mathrm{~m} / \mathrm{s}$ at $X=15.8 \mathrm{~mm}$.

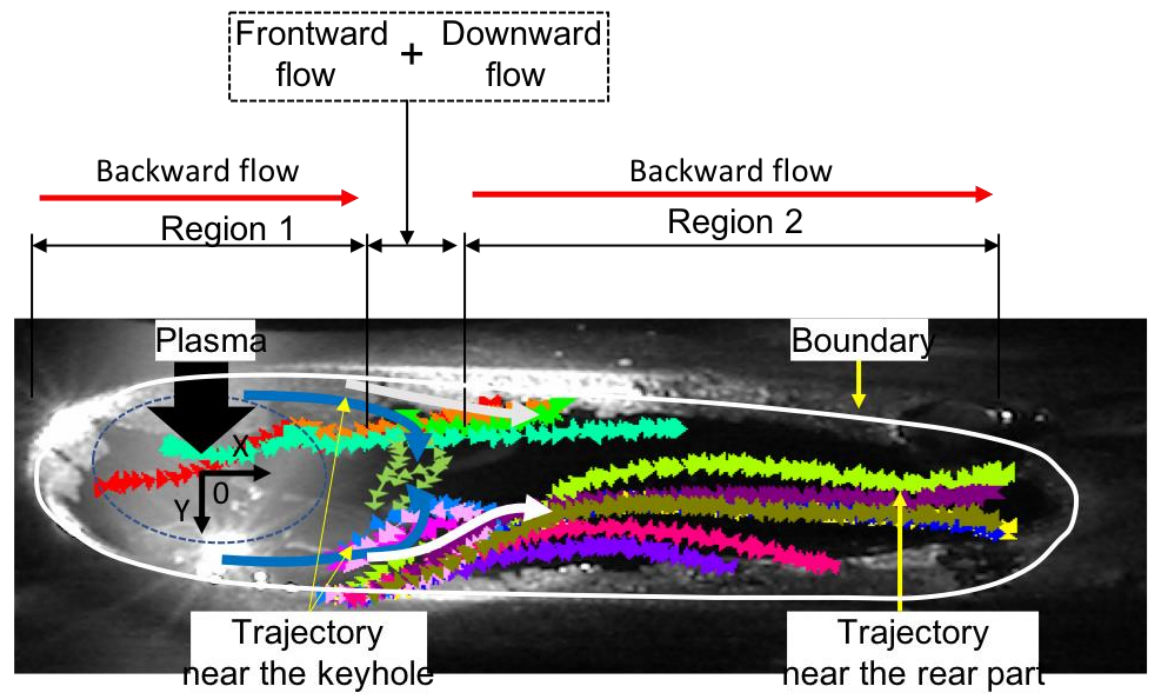

(a) $1.6 \mathrm{~mm}$

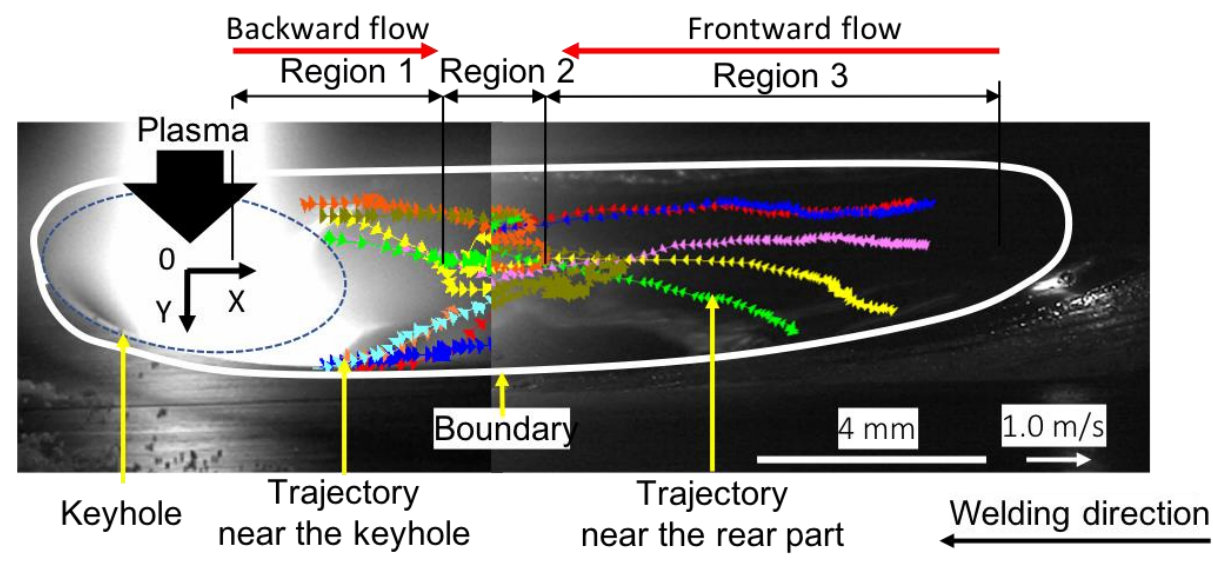

(b) $2.4 \mathrm{~mm}$

Fig 8. Convective pattern on the top surface of weld pool.

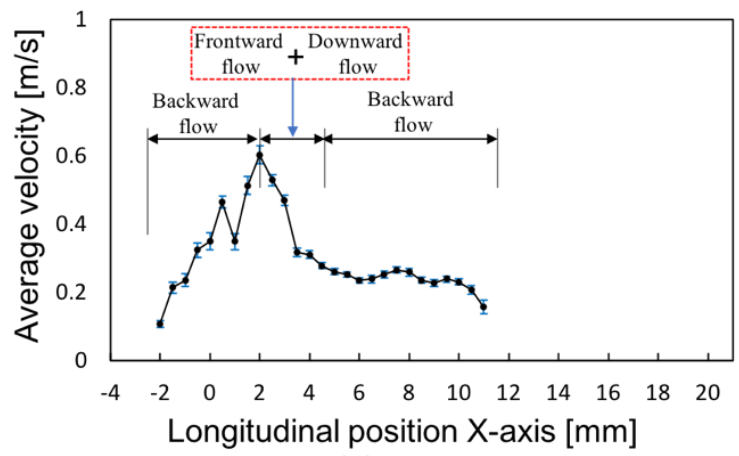

(a) $1.6 \mathrm{~mm}$

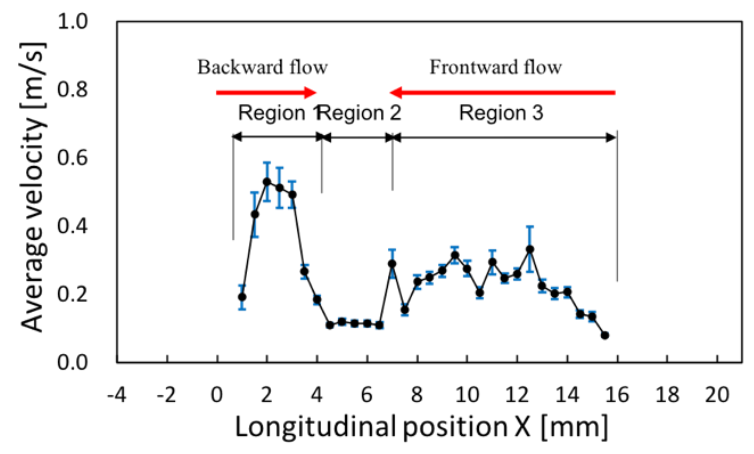

(b) $2.4 \mathrm{~mm}$

Fig 9. Distribution of average flow velocity on the top surface of weld pool. 
Convective pattern on the bottom surface of weld pool is presented in Fig. 10 (a) and (b) corresponding to $1.6 \mathrm{~mm}$ and $2.4 \mathrm{~mm}$, respectively. There is one convective pattern in backward tendency in both cases of $1.6 \mathrm{~mm}$ and $2.4 \mathrm{~mm}$. Zirconia particles came mainly from the rear edge of keyhole before accelerating in backward tendency toward the ending weld pool. The velocity of particles is increased much from sides of weld pool toward the centre line of weld pool ( $Y=0 \mathrm{~mm})$. Distribution of average flow velocity on the bottom surface of weld pool is displayed in Fig 11 (a) and (b) corresponding to the nozzle diameter of $1.6 \mathrm{~mm}$ and $2.4 \mathrm{~mm}$, respectively. The maximum velocity in both cases is located just behind keyhole on the centre line $(\mathrm{Y}=0 \mathrm{~mm})$ of weld pool (within high temperature zone). Around the keyhole, the flow velocity is much higher in case of $2.0 \mathrm{~mm}$ due to the thermal pinch effect as mentioned above. Within $X=0.0 \sim 3.0 \mathrm{~mm}$, velocity in case of $2.0 \mathrm{~mm}$ is decreased quickly. Meanwhile the velocity in case of $2.4 \mathrm{~mm}$ is gradually decreased. The maximal velocity was about $1.17 \mathrm{~m} / \mathrm{s}$ at $X=1 \mathrm{~mm}$ in the case of $1.6 \mathrm{~mm}$ and about $0.82 \mathrm{~m} / \mathrm{s}$ at $X=1 \mathrm{~mm}$ in case of $2.4 \mathrm{~mm}$. At $X=3 \mathrm{~mm}$, the velocity was about $0.43 \mathrm{~m} / \mathrm{s}$ in case of $1.6 \mathrm{~mm}$ and about $0.41 \mathrm{~m} / \mathrm{s}$ in case of $2.4 \mathrm{~mm}$. From $X=3.0 \mathrm{~mm}$ until the ending weld pool, the velocity was gradually decreased in both cases. The minimal velocity was about $0.2 \mathrm{~m} / \mathrm{s}$ at $X=12.5 \mathrm{~mm}$ in the case of $1.6 \mathrm{~mm}$ and it was about $0.075 \mathrm{~m} / \mathrm{s}$ at $\mathrm{X}=13 \mathrm{~mm}$ in the case of $2.4 \mathrm{~mm}$.

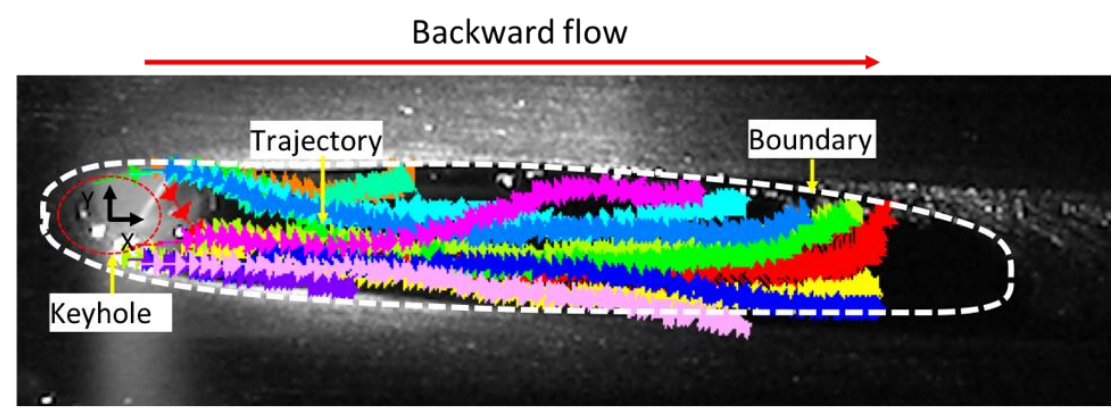

(a) $1.6 \mathrm{~mm}$

Backward flow

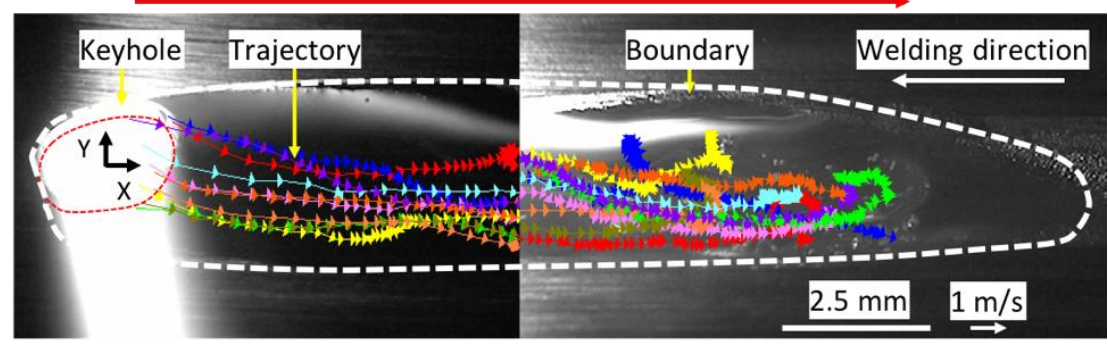

(b) $2.4 \mathrm{~mm}$

Fig 12. Convective pattern on the bottom surface of weld pool.

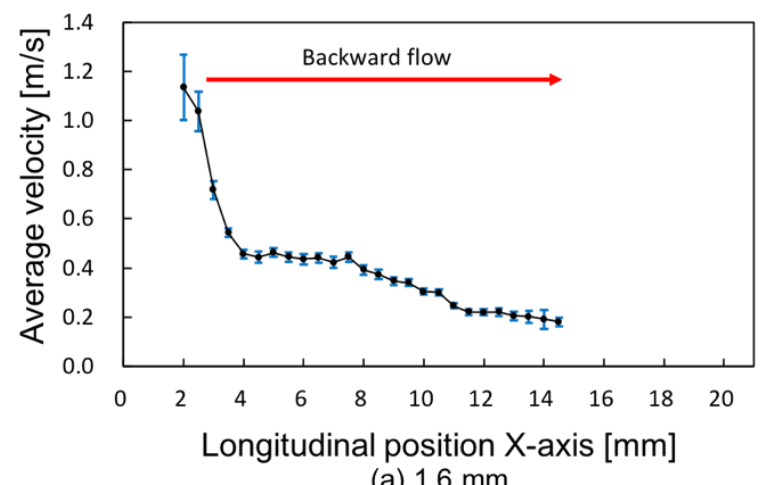

(a) $1.6 \mathrm{~mm}$

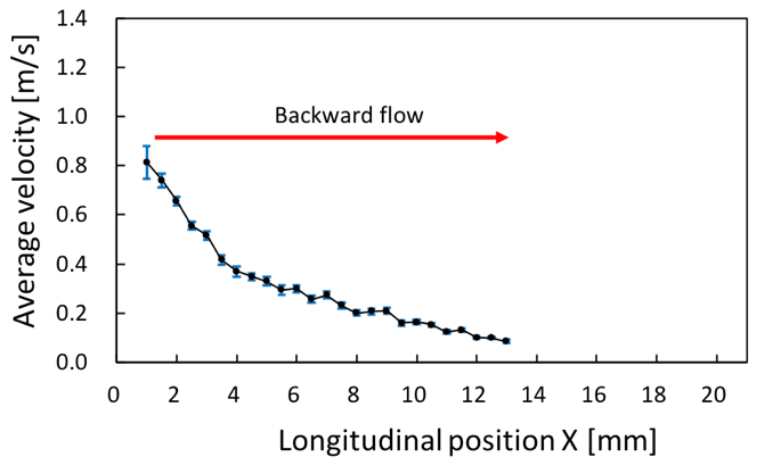

(b) $2.4 \mathrm{~mm}$

Fig 11. Distribution of average flow velocity on the bottom surface of weld pool. 


\subsection{Convective patterns inside weld pool}

Three-dimensional convective patterns inside weld pool in the cases of $1.6 \mathrm{~mm}$ and $2.4 \mathrm{~mm}$ are indicated in Fig. 12 (a) and (b) respectively. It can be seen that there are two movement trends of tungsten particles inside weld pool in both cases. After passing frond side of keyhole, several particles were moved in upwards and backwards near the top surface and several other particles was moved in downwards and backwards near the bottom surface. From this movement of tracer particles, it can be considered that there are two convective patterns: (1) in upward tendency near the top surface and (2) in downward tendency near the bottom surface. As a result of convection inside weld pool, we are considering that two convection flows as mentioned above produced an eddy pair with upper eddy in accordance with convection near the top surface and lower eddy in accordance with convection near the bottom surface. In the case of $2.4 \mathrm{~mm}$, since tungsten particles belonged to near the top surface, they are strongly moved in upward tendency, and then backward tendency toward $X=4 \sim 6 \mathrm{~mm}$ behind keyhole. After that it sunk to neutral place of base metal before moving back to nearby keyhole. Since tungsten particles belonged to near bottom surface, it strongly moved in downward tendency, and then in backward tendency toward $X=5 \sim 6 \mathrm{~mm}$ behind keyhole. It then tried to move upward to nearby neutral place of base metal before moving back to nearby keyhole. From these results, it can be considered that there are two convective patterns in the case of $2.4 \mathrm{~mm}$. Convective pattern in upward tendency is much larger than convective pattern in downward tendency. In the case of $1.6 \mathrm{~mm}$, since tungsten particles belonged to the eddy near top surface, they moved in upward tendency, and then in backward tendency toward $X=2 \sim 3.5 \mathrm{~mm}$ behind keyhole. After that it sunk to neutral place of base metal before moving back to near keyhole. Since tungsten particles belonged to near the bottom surface, it strongly moved in downward tendency, and then backward tendency toward $X=10 \sim 11 \mathrm{~mm}$ behind keyhole. It then tried to transport upward direction before moving back to near keyhole. As a result, it can be considered that two convection flows were formed and convective pattern in downward tendency is much larger and stronger than that in upward tendency. A large amount of plasma gas flow is pushed out in downward direction through keyhole in the case of $1.6 \mathrm{~mm}$. This caused a larger eddy part near the bottom surface. Meanwhile a large amount of plasma gas flow is flowed along the top surface in the case of $2.4 \mathrm{~mm}$. This caused a larger eddy part near the top surface. This tendency is deduced from the difference in the cross-sections of the keyholes shown in Fig. 5 . The maximal velocity of particles inside weld pool is about $0.33 \mathrm{~m} / \mathrm{s}$ on the bottom surface in the case of $1.6 \mathrm{~mm}$ and about $0.31 \mathrm{~m} / \mathrm{s}$ on the top surface in the case of $2.4 \mathrm{~mm}$.

Three-dimensional convective patterns inside weld pool in the cases of $1.6 \mathrm{~mm}$ and $2.4 \mathrm{~mm}$ viewed parallel with Y-axis are presented in Fig. 13 (a) and (b) respectively. Tungsten particles are oscillated within $Z=0.3 \sim 4.3 \mathrm{~mm} \& X=0 \sim 9.8 \mathrm{~mm}$ in the case of $1.6 \mathrm{~mm}$ and $Z=0.4 \sim 4.4 \mathrm{~mm} \& X=$ $0 \sim 7.3 \mathrm{~mm}$ in the case of $2.4 \mathrm{~mm}$. In the case of $1.6 \mathrm{~mm}$, the convective pattern near the bottom surface is much larger and longer than convective pattern near the top surface. The maximal velocity is located on the convective pattern near the bottom surface. In the case of $2.4 \mathrm{~mm}$, the convective pattern near top surface is much larger and longer than convective pattern near the bottom surface. The maximal velocity is located on the convective pattern near the top surface. The highest position of convective pattern in the case of $1.6 \mathrm{~mm}$ (at $Z=0.3 \mathrm{~mm}$ ) is a little bit higher than case of $2.4 \mathrm{~mm}(Z$ $=0.4 \mathrm{~mm}$ ). These phenomena may correspond to a little bit humping on the top surface as seen in Fig. 5. The lowest position of convective pattern in case of $2.4 \mathrm{~mm}$ (at $Z=4.4 \mathrm{~mm}$ ) is a little bit lower than the case of $2.4 \mathrm{~mm}$ (at $Z=4.3 \mathrm{~mm}$ ). These phenomena may correspond to a little bit humping on the bottom surface as seen in Fig. $\mathbf{5}$.

Three-dimensional convective patterns inside weld pool in the cases of $1.6 \mathrm{~mm}$ and $2.4 \mathrm{~mm}$ viewed parallel with Z-axis are presented in Fig 14 (a) and (b) respectively. Tracer particles are oscillated within $\mathrm{Y}=-2.0 \sim 2.3 \mathrm{~mm} \& \mathrm{X}=0 \sim 10.8 \mathrm{~mm}$ in case of $1.6 \mathrm{~mm}$ and $-3.8 \sim 4.5 \mathrm{~mm} \& \mathrm{X}=0.0 \sim$ $8.3 \mathrm{~mm}$ in the case of $2.4 \mathrm{~mm}$. It can be clearly seen that the movement range of tracer particles along $\mathrm{Y}$ axis in the case of $2.4 \mathrm{~mm}$ is much larger than case of $1.6 \mathrm{~mm}$. But the movement range along $\mathrm{X}$ axis 
in case of $1.6 \mathrm{~mm}$ is much longer than case of $2.4 \mathrm{~mm}$. In the case of $2.4 \mathrm{~mm}$, two the convective patterns are located in symmetry through the centre line of weld pool $(X=0)$ in clockwise and counter clockwise directions. In the case of $1.6 \mathrm{~mm}$, it seems that there is only one convective pattern in clockwise direction with axis of symmetry is centre line of weld pool. The change of weld bead appearance and keyhole profile are shown in Fig 5. In the case of $1.6 \mathrm{~mm}$, the weld bead and keyhole size are smaller than that in the case of $2.4 \mathrm{~mm}$, especially near top surface. In both cases of $1.6 \mathrm{~mm}$ and $2.4 \mathrm{~mm}$, it can be seen to be a good weld bead without welding defects. For the velocity distribution, it can be seen that the maximal velocity in the case of $1.6 \mathrm{~mm}$ is slightly smaller than the case of $2.4 \mathrm{~mm}$. In both cases, the maximal velocity is located as far as the centre line (about $\mathrm{Y}=-1.5$ $\mathrm{mm}$ or $Y=1.5 \mathrm{~mm}$ in the case of $1.6 \mathrm{~mm}$ and $Y=-3.6 \mathrm{~mm}$ or $Y=3.6 \mathrm{~mm}$ in the case of $2.4 \mathrm{~mm}$ ). In the case of $1.6 \mathrm{~mm}$, the maximal velocity of $0.31 \mathrm{~m} / \mathrm{s}$ is located at $Y=-1.4 \mathrm{~mm}$ or $Y=1.4 \mathrm{~mm}$. In the case of $2.4 \mathrm{~mm}$, the maximal velocity is about $0.33 \mathrm{~m} / \mathrm{s}$ at about $Y=-3.0 \mathrm{~mm}$ or $Y=3.0 \mathrm{~mm}$. The velocity near the centre line is $0.14 \mathrm{~m} / \mathrm{s}$ and $0.15 \mathrm{~m} / \mathrm{s}$ in cases of $1.6 \mathrm{~mm}$ and $2.4 \mathrm{~mm}$, respectively.

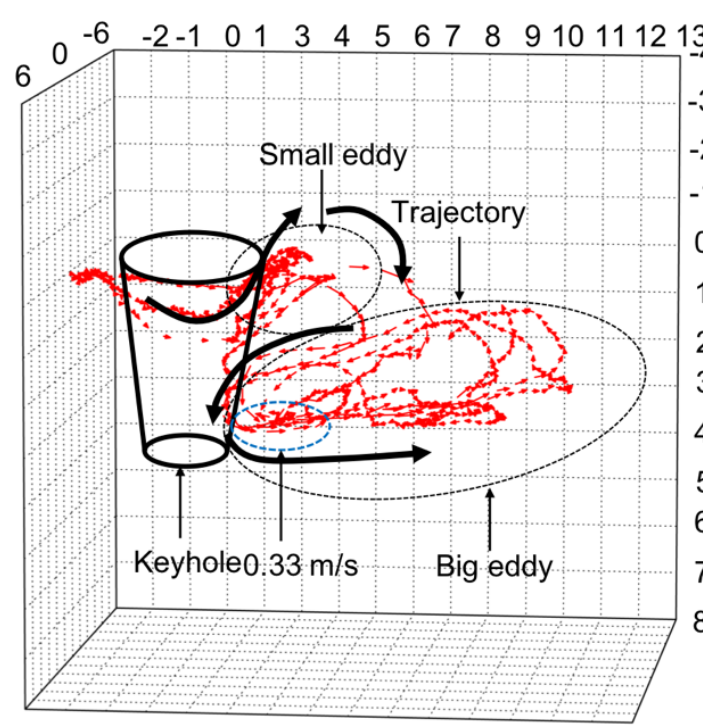

(a) $1.6 \mathrm{~mm}$

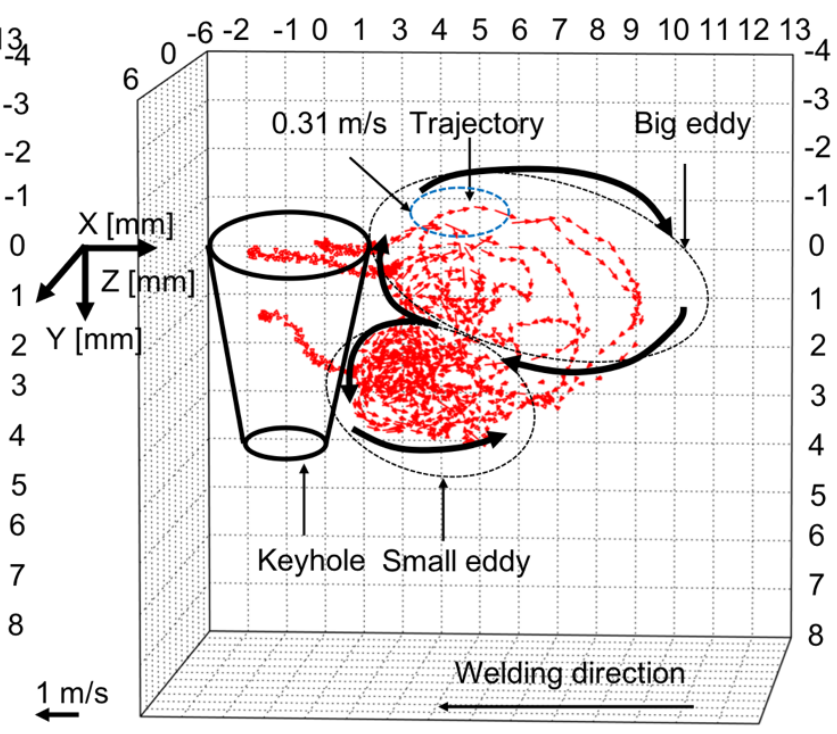

(b) $2.4 \mathrm{~mm}$

Fig 12. Three-dimensional convective patterns inside weld pool.

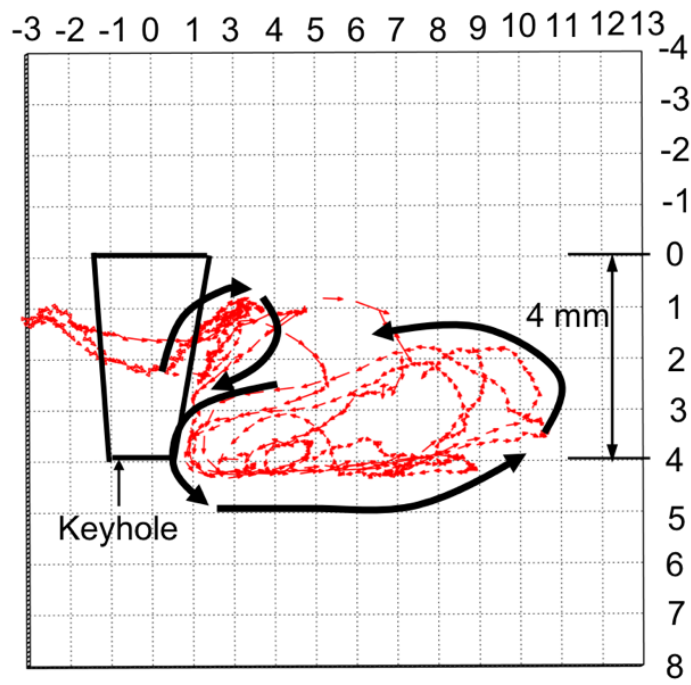

(a) $1.6 \mathrm{~mm}$

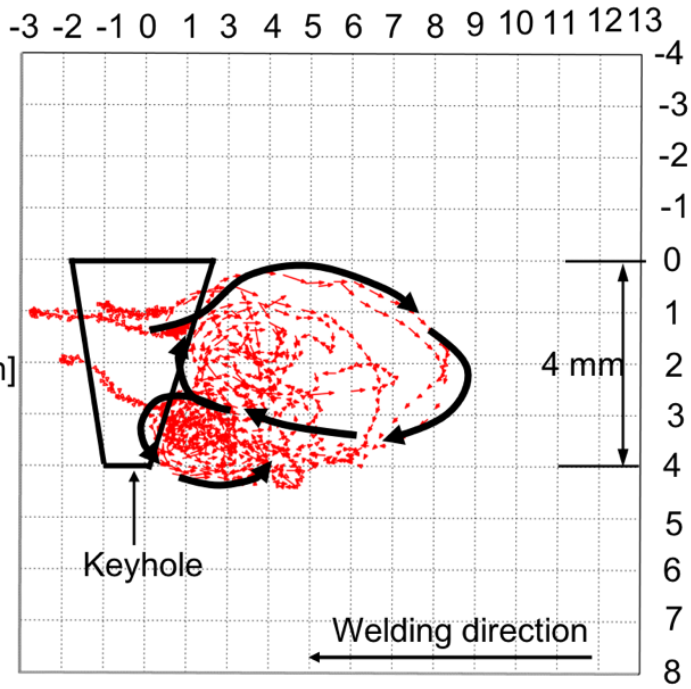

(b) $2.4 \mathrm{~mm}$

Fig 13. Three-dimensional convective patterns inside weld pool viewed parallel to Y-axis. 


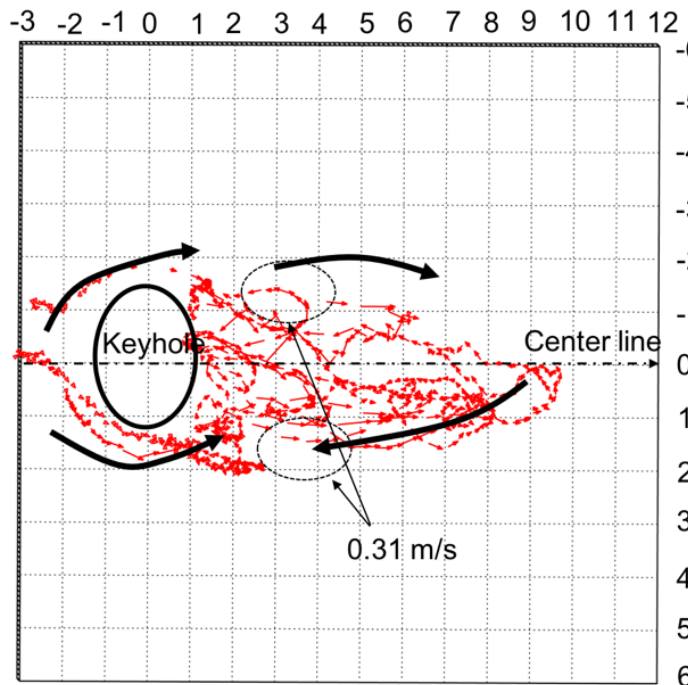

(a) $1.6 \mathrm{~mm}$

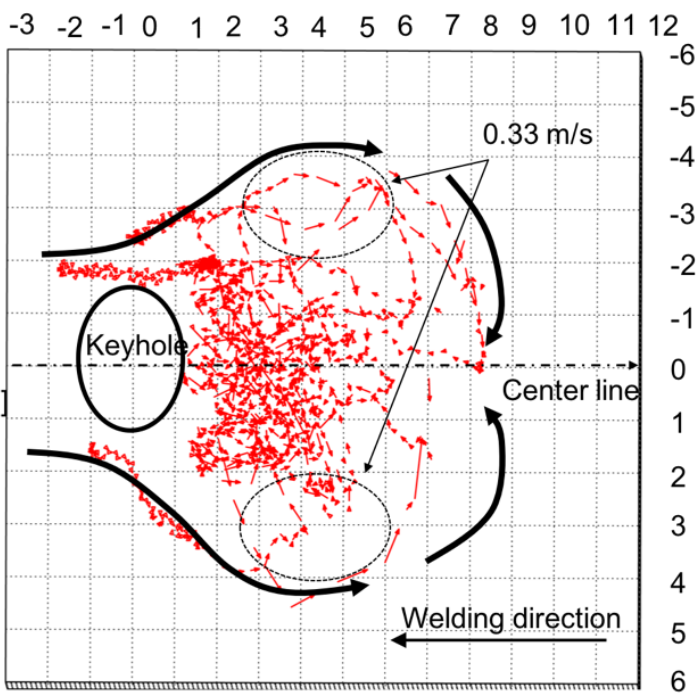

(b) $2.4 \mathrm{~mm}$

Fig 14. Three-dimensional convective patterns inside weld pool viewed parallel to Z-axis.

\section{Discussion}

In the case of $1.6 \mathrm{~mm}$ nozzle diameter, because of the smaller nozzle diameter, the arc pressure and the heat flux are increased much, especially near the centre of torch in comparison to the case of diameter $2.4 \mathrm{~mm}$ [4]. As a result, the keyhole is steeper as seen in Fig. 5. Furthermore, the shear force component in downward direction along the keyhole surface is increased. As a result, the convection is tended in frontward direction to cause the higher average temperature than in the case of $2.4 \mathrm{~mm}$, especially near the keyhole and the high temperature zone as indicated in Fig. 6. On the top surface, the high temperature zone is shifted in frontward direction toward the keyhole with the maximal temperature is about $1930 \mathrm{~K}$ located at $X=2.5 \sim 4.0 \mathrm{~mm}$ region, meanwhile the maximal temperature in the case of $2.4 \mathrm{~mm}$ is about $1895 \mathrm{~K}$ located at $\mathrm{X}=4.5 \sim 6.0 \mathrm{~mm}$ region. On the bottom surface, the temperature distribution tendency is similar in both cases with the highest temperature is located just behind the keyhole and the temperature near the centre line is higher than the edge of the weld pool. In this case, the downward convection pattern in the case of $1.6 \mathrm{~mm}$ increases the heat on the bottom surface and the smaller keyhole size on the bottom surface, the higher average temperature distribution on the bottoms surface in the case of $1.6 \mathrm{~mm}$ as seen in Fig. 7. The maximal temperature was located just behind keyhole. The maximal temperature was about $1920 \mathrm{~K}$ in the case of $1.6 \mathrm{~mm}$ in comparison to $1890 \mathrm{~K}$ in the case of $2.4 \mathrm{~mm}$. For the temperature on the bottom surface, it was gradually decreased from the keyhole toward the rear edge of weld pool. In the case of $2.4 \mathrm{~mm}$, the plasma arc column was wider and the arc pressure was lower as mentioned above resulting the increase of shear force component in upward direction and backward direction. This resulted a larger inclination angle of the rear keyhole edge in comparison to nozzle $1.6 \mathrm{~mm}$, especially near the top surface of weld pool. Furthermore, the inclination angle of the front keyhole edge was larger in the case of $2.4 \mathrm{~mm}$ with $18^{0}$ in comparing $14^{\circ}$ in the case of $1.6 \mathrm{~mm}$. As a result, the keyhole, the weld pool and the weld bead on the top surface in the case of $2.4 \mathrm{~mm}$ tend to be wider in the case of $1.6 \mathrm{~mm}$ as seen in Fig. 5. As shown in Fig. 6, the high temperature zone on the top surface of the weld pool is corresponded with the alterative zone of weld pool convection flow in both cases. As mentioned above, the maximal temperature was located around $X=2.5 \sim 4.5 \mathrm{~mm}$ in the case of $1.6 \mathrm{~mm}$ and $X=$ $4.5 \sim 6.5 \mathrm{~mm}$ in the case of $2.4 \mathrm{~mm}$. These results were suitable with the convection inside weld pool and on the top surface. In the case of $2.4 \mathrm{~mm}$ nozzle diameter, the minimal velocity of convection flow was located around $X=4.0 \sim 6.0 \mathrm{~mm}$ corresponding to high temperature zone. On the other hand, the convection flow on the top surface of weld pool was also diverted from translational motion to the circulated motion at $\mathrm{X}=4.5 \sim 6.5 \mathrm{~mm}$. Furthermore, the convection flow inside weld pool were 
also altered at $X=4 \sim 6 \mathrm{~mm}$ zone. These results matched with the heat transportation of the weld pool. On the bottom surface, only one convection flow from the keyhole toward the rear weld pool matched with the direction of the heat transportation. In the case of $1.6 \mathrm{~mm}$ nozzle diameter, the velocity of zirconia particles on the top surface of weld pool was gradually decreased before diverting from backward direction to frontward direction at $X=2.5 \sim 4.0 \mathrm{~mm}$ (high temperature zone). After that the velocity of zirconia particles was rapidly increased in downward direction around $X=2.0$ mm (see Fig. 8 and Fig. 9) with high velocity. Tungsten particles moving inside weld pool was also altered from backward direction to downward direction at high temperature zone $(X=2.5 \sim 3.5 \mathrm{~mm})$ with low velocity before it is accelerated in downward direction with the maximal velocity at the bottom surface of weld pool. For the convection flow on the bottom surface, because the maximal temperature was located just behind the keyhole and gradually decreased toward the rear edge of weld pool, only one direction of material flow was in backward tendency with the maximal velocity located just behind the keyhole. However, the maximal flow velocity was much higher in the case of $2.0 \mathrm{~mm}$ due to a smaller nozzle diameter as explained above.

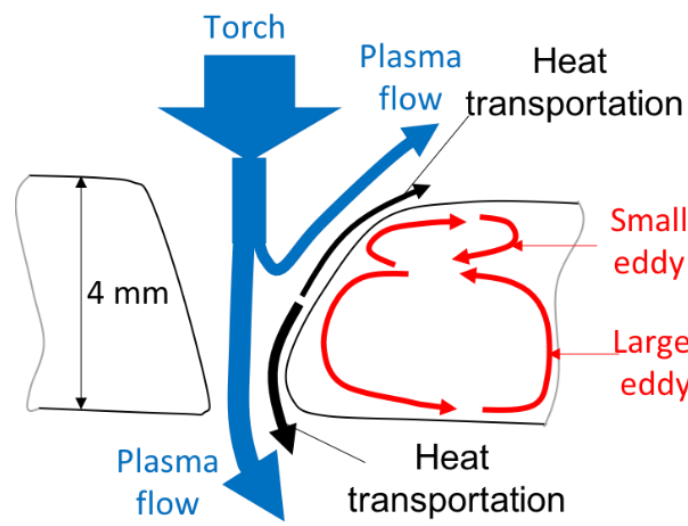

Welding direction

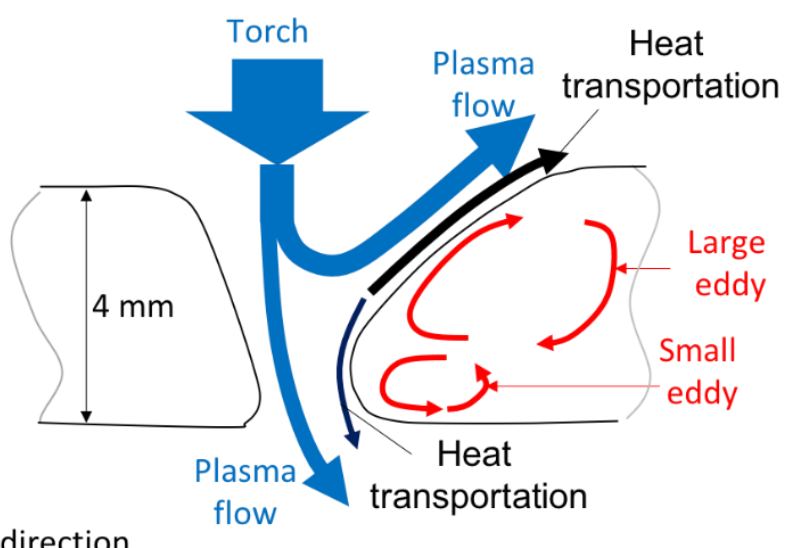

(b) $2.4 \mathrm{~mm}$

(a) $1.6 \mathrm{~mm}$

ortation of weld pool.

Fig 15. Schematic illustration of eddies and heat transportation of weld pool.

A schematic illustration of the relationship between the profile of eddies and heat transportation of weld pool is indicated in Fig 15 (a) and (b). In this case, the weld bead appearance and the keyhole profile are changed depending on the nozzle diameter. In both cases, the heat is transferred in both sides: upwards and downwards. However, the heat is mainly transported in upward direction in the case of $2.4 \mathrm{~mm}$ due to a large inclination angle of keyhole wall. Meanwhile the heat is transported mainly in downward direction in the case of $1.6 \mathrm{~m}$ due to a steep keyhole wall. In the case of $1.6 \mathrm{~mm}$, due to the thermal pinch effect, the energy density is higher and plasma column are furthermore constricted. Consequently, the plasma flow and energy through the keyhole is much increased. This created a steeper keyhole and the inclination angle of rear part of the keyhole reduced significantly, especially near the top surface. As a result, the plasma gas flow inside weld pool is transported furthermore in downward tendency. This produced much the heat on the bottom surface. Therefore, only a small amount of plasma gas flow was pushed in upward tendency and along the top surface causing a small eddy near the top surface. As a consequence, the downward eddy near the bottom surface is larger and longer than the upward eddy near the top surface. In the case of $2.4 \mathrm{~mm}$, a large amount of plasma flows along the keyhole surface in upward direction and along the weld pool surface in backward direction. The energy density is largely decreased and constriction of plasma arc column is reduced much in comparison to the case of $1.6 \mathrm{~mm}$. On the other hand, since a large part of plasma gas flow pushed the molten metal in upward direction and backward direction, it increased the inclination angle of rear keyhole edge in order to transport the heat in upwards. As a consequence, the convective pattern caused by the plasma flow along the top surface is increased. Therefore, this 
pattern becomes larger than convective pattern caused by the plasma flow along the keyhole wall in downward tendency. This also caused the movement of tungsten particles in the case of $2.4 \mathrm{~mm}$ is different to the case of $1.6 \mathrm{~mm}$. The number of tungsten particles moved nearby the top surface in the case of $2.4 \mathrm{~mm}$, meanwhile it moved nearby the bottom surface in the case of $1.6 \mathrm{~mm}$.

\section{Conclusions}

In this paper, the comprehensive experiment of weld pool in PKAW was conducted to discuss the influence of nozzle diameter on the weld pool formation process. The main conclusions are elucidated follows. It is found that, in PKAW, generally two large eddies are produced in the weld pool just behind the keyhole mainly through the shear force by the plasma flow acting on the weld pool surface. The magnitude, extent and direction of the shear force is thought to be determined primarily by the keyhole shape. Thus, the relative strength of each eddy largely changes depending on the welding conditions through the change in the keyhole shape. This relative strength of each eddy is considered to decisively govern the heat transport in the weld pool and also the occurrence of the welding defects. The eddy part near the top surface is much larger and longer in case of 1.6 $\mathrm{mm}$. Meanwhile the eddy part near the bottom surface became much bigger and longer in case of 2.4 $\mathrm{mm}$. The heat transportation was mainly in upward direction in the case of $2.4 \mathrm{~mm}$ and in downward direction in the case of $1.6 \mathrm{~mm}$. The steeper keyhole wall produced by the strong plasma flow, accelerated through the small diameter constriction nozzle, induces strong downward shear force inside the keyhole to produce a lager eddy and longer near the lower part of keyhole inside weld pool in case of diameter $1.6 \mathrm{~mm}$. Due to a larger size of nozzle in case of diameter $2.4 \mathrm{~mm}$, the plasma column is wider. This reduced the strength of downward part of shear force, meanwhile increased the strength of upward part and backward part of shear force along the surface upper part of keyhole wall and the top surface of weld pool in outward direction.

Author Contributions: N.H.M. wrote the draft and revised the paper; N.V.A. collected the data, wrote the draft, and responded to the journal; T.T.N. and D.H.T. discussed the results; H.T.N analysis the experimental data. All authors discussed the results and contributed to the final manuscript.

Funding: No funding support was received for this paper.

Conflicts of Interest: The authors declare that there is no conflict of interest regarding the publication of this paper.

\section{References}

[1] Anh Van Nguyen, Shinichi Tashiro, Hanh Bui Van and Manabu Tanaka, "Influence of Pilot Gas Composition on Convective Pattern of Weld pool surface in PKAW," Quarterly Journal of the Japan welding society, vol. 35, pp. 98-102, 2017.

[2] M. J. Tomsic and C. E. Jackson, "Energy distribution in keyhole mode plasma arc welds," Welding journal, March, pp. 109-116, 1974.

[3] J. C. Metcalfe, M. B. C. Quigley, “Heat transfer in Plasma-arc welding," Welding journal, March, pp. 99-104, 1975.

[4]. Manabu Tanaka and Shinichi Tashiro, "A study of the thermal pinch effect of welding arcs," Quarterly journal of japan welding society, vol.25, pp. 336-342, 2007.

[5] J. K. Martikainen and T. J. I. Moiso, "Investigation of the effect of welding parameters on weld quality of plasma arc keyhole welding of structure steels," Welding journal, July, pp. 329-340, 1993.

[6] Jia Chuan-bao, Wu Chuan-song and Zhang Yu-ming, "Sensing controlled pulse key-holing condition in plasma arc welding," Trans. Nonferrous Met. Soc. China, no. 19 pp. 341-346, 2009.

[7] W. Lucas, Tig and plasma welding, Woodhead Publishing, 1990. 
[8] Zu Ming Liu, ShuangLin Cui, Zhen Luo, Changzhen Zhang, ZhengMing Wang and YuChen Zhang, "Plasma arc welding process variants and its recent developments of sensing controlling and modeling," Journal of manufacturing processes, no. 23, pp. 315-327, 2016.

[9] R. J. Hung, G. J. Zhu, The variable polarity plasma arc welding process: characteristics and performance, The University of Alabama in Huntsville (report of Nasa contract), 1991.

[10] Kunio Narita, Kenji Takagi, Takehiro Kimura and Akio Mitsui, "Plasma arc welding of pipelines: a study to optimize welding conditions for horizontal fixed joints of mild steel pipes," Int. J. press. Ves. E Piping, vol. 3, pp. 233-266, 1975.

[11] Bin Xu, Fan Jiang, Shujin Chen, Manabu Tanaka, Shinichi Tashiro, Nguyen Van Anh, “Numerical analysis of plasma arc physical characteristics under additional constraint of keyhole," Chinese Physics B, vol. 27, 034701, 2018

[12] Bin Xu, Shujin chen, Shinchi Tashiro, Fan Jiang, Nguyen Van Anh, Manabu Tanaka, “Material flow analyses of high-efficiency joint process in VPPA keyhole flat welding by X-ray transmission system," Journal of Cleaner Production, vol. 250, 119450, 2020.

[13] J. C. Metcalfe and M. B. C. Quigley, “Keyhole stability in Plasma keyhole arc welding," Welding journal, November, pp. 401-404, 1975.

[14] S. B. Zhang and Y. M. Yang, "Efflux plasma charge based sensing and control of joint penetration during keyhole plasma arc welding," Welding journal, vol. 80, pp. 157-162, 2001.

[15] C. S. Wu, C. B. Jia and M. A. Chen, “A control system for keyhole plasma arc welding of stainless-steel plates with medium thickness," Welding journal, vol. 89, pp. 225-231, 2010.

[16] Z M Liu, C S Wu and M A Chen, "Visualizing the influence of the process parameters on the keyhole dimensions in plasma arc welding," Meas. Sci. Technol, vol. 23, 105603 (9pp), 2012.

[17] Zuming Liu, Chuan Song Wu and Jinqiang Gao, “Vision-based observation of keyhole geometry in plasma arc welding, International journal of thermal science, vol. 63, pp. 38-45, 2013.

[18] Y. M. Zhang and S. B. Zhang, “Observation of the keyhole during plasma arc welding," Welding journal, February, pp. 53-58, 1999.

[19] Z. M. Liu, C. S. Wu, Y. K. Liu, Z. Luo, “Keyhole behaviors influence weld defects in plasma arc welding process," Welding journal, no. 9, pp. 281-290, 2015.

[20] Goukai Zhang, Chuan Song Wu and Zuming Liu, “Experimental observation of both keyhole and its surrounding thermal field in plasma arc welding," International journal of heat and mass transfer, vol. 70, pp. 439-448, 2014.

[21] C. S Wu, W. Zheng and M. A. Chen, "Improving the prediction accuracy of keyhole establishment time in plasma arc welding," Numerical heat transfer, Part A, no. 668, pp. 420-432, 2014.

[22] Xiaoxia Jian and C. S Wu, "Numerical analysis of the coupled arc-weld pool-keyhole behaviors in stationary plasma arc welding," International journal of heat and mass transfer, no. 84, pp. 839-847, 2015.

[23]. Yan Li, Yanhui Feng, Yafei Li, Xinxin Zhang and Chuan Song Wu, "Plasma arc and weld pool coupled modeling of transport phenomena in keyhole welding," International journal of heat and mass transfer, no. 92, pp. 628-638, 2016.

[24] Jiajing Pan, Shengsun Hu, Lijun Yang and Shujin Chen, "Numerical analysis of the heat transfer and material flow during keyhole plasma arc welding using a fully coupled tungsten plasma anode model," Acta materialia, vol. 118, pp. 221-229, 2016. 
[25] Manabu Tanakaa and J J Lowke, "Predictions of weld pool profiles using plasma physics," J. Phys. D Appl. Phys., vol. 40, pp. R1-R23, 2017.

[26] Nguyen Phi Long, Yusuke Katada, Yasunori Tanaka, Yoshihiho Uegi and Yoshihiro Yamaguchi 2012, "Cathode diameter and operating parameter effects on hafnium cathode evaporation for oxygen plasma cutting arc," J. Phys. D: Appl. Phys. Vol. 45, 435203, 2012. 